\section{Setting the facts straight on Wikipedia}

\author{
John Launer
}

If you enter almost any name or topic into your search engine, the first item listed will probably be from Wikipedia. It has become, by default, the world's chief source of information. The quality of information you find there will of course be highly variable. As critics point out, anyone with access to a computer can edit a Wikipedia page. You can insert incorrect information, or add falsehoods out of malice, or as a prank. ${ }^{1}$ You can promote your own agenda, and repeatedly edit articles in the hope that your opponents will give up. You can do all of this anonymously. Schools and universities warn students to be extremely cautious about using Wikipedia, ${ }^{2}$ while journals discourage contributors from citing it. ${ }^{3}$ In spite of this, enthusiasts for Wikipedia point out that its accuracy has been demonstrated in a number of studies, including comparisons with Encyclopedia Britannica and the database of the US National Cancer Institute. $^{4}$ They argue that it allows continuous updating and improvement, in a way that conventional academic sources like journals cannot. Anyone who objects to its content, they suggest, can amend this instead of complaining, and test out whether the experience of doing so is really as negative as the critics suggest.

Like many other people, I have a lovehate relationship with Wikipedia. In theory, I am sceptical about it. In practice I often use it, because it is so convenient. Until recently, I never tried to edit anything there. However, there is one particular historical figure I know a great deal about, because I have written a book about her (the Russian psychiatrist Sabina Spielrein ${ }^{6}$ ), and I have been aware for a long time that the Wikipedia article about her was sketchy and inaccurate. It focussed mainly on her brief affair with someone more famous, rather than her 30 year career in psychiatry. I was annoyed by this, but did nothing about it. Then it dawned on me that this was an arrogant and stupid attitude to take. Her Wikipedia page receives around 1000 hits a week. A readable and well-informed article there would reach vastly more people than I could ever hope would read my book. I decided to edit the article myself, and

Correspondence to Dr John Launer, Faculty Development, Health Education England, Stewart House, 32 Russell, London WC1B 5DN, UK: john.launer@nwl.hee.nhs.uk
I learned a great deal about Wikipedia by doing so.

I registered as an editor, which only takes a couple of minutes. I used my own name, as I wanted to be open about what I was doing. Then I started to edit a few things in the article that I knew were wrong. One of these was the name of Spielrein's father. The article referred to him by Jewish name, Naftul, but I knew he had used his Russian name, Nikolai, for most of his life. I amended the page accordingly, and made a few similar changes.

\section{ABRASIVE MESSAGE}

Within a few hours, my edits had all been 'undone'-in other words, reversed by someone else. I also received an abrasive message, pointing out that I had cited no evidence for any of them. At first I felt aggrieved. Then I realised that asking me to provide my sources was no different from anything my colleagues at the PMJ might do when dealing with journal submissions. I exchanged a few messages with the person who had challenged me. He turned out to be a Dutch rabbi. Evidently, he was concerned I might be a Russian nationalist, who had made the details up myself for political reasons, and without any information to support them. Once I knew this, I did the edits again, adding my sources. No-one challenged me.

Encouraged by this, I continued to edit the entire article. I discovered how many different kinds of junk you can find on a Wikipedia page. In Spielrein's case, this consisted of tendentious facts, rumours dressed up as certainties, incorrect or irrelevant references, and much else. I also found out how clunky the editing apparatus is. You might expect Wikipedia to have a referencing system and a style manual as easy to master as an academic journal. It does not. Instead, it has an elaborate system of technical pages, as well as 'talk pages,' and 'user pages'. Ostensibly these are meant to help editors. In practice, they appear to cater mainly for the kind of obsessive young 'techies' who currently seem to form the majority of Wikipedia's volunteers. ${ }^{7}$ Many of the comments there consist of cryptic abbreviations, strung together in an ill-tempered tone.

Fortunately it is possible to ignore this. You can learn how to edit a page just by trying it out, and seeing what response you get. If you run into difficulties, you can ask for help on your own personal 'talk page', making it clear you are a beginner. A volunteer will get back to you, probably from India or the United States, and usually in a few minutes. You can work your way through an article line by line, just as you would do when amending an essay or a submission to a journal. I found that editing a Wikipedia article takes just as much time as any other piece of professional writing, but perhaps that is reasonable. In the end, I succeeded in rewriting the entire article. If you Google the name Sabina Spielrein, you can see the result.

\section{LEARNING EXERCISE}

The experience has made me feel better disposed towards Wikipedia. I agree with the editorial in the $B M J$ last year, proposing that 'Everyone should have research practices at least as good as the Wikipedians'. ${ }^{8}$ I would go further. I think that editing Wikipedia could be a useful learning exercise for medical students and junior doctors. It could help them understand how knowledge is created, and how consensus is established. It would improve their ability to spot questionable information, not just on Wikipedia itself, but more widely. It might even be worthwhile to prescribe this for them as an exercise in critical appraisal. For doctors who have never written academic articles, or succeeded in publishing any, Wikipedia would be an excellent laboratory for practising the art of writing, in short bursts, with fairly little risk, and getting an immediate response.

There is an even better reason to write for Wikipedia. Most people believe what it says, whether or not they should. Words carry magical power. Unless people happen to know evidence to the contrary, they will assume that what they read is correct. If you read that Albert Einstein's middle name was Franz, it will stay in your mind, even though it is untrue. In due course you may well pass it on, saying "I'm sure I read it somewhere". Out of the 8000 people who consult Wikipedia every second, ${ }^{9}$ the vast majority are unlikely to question what they read, or have the time or motivation to check it. They too will pass on what they remember. By setting the facts straight on Wikipedia, you will do everyone a service.

Twitter Follow John Launer at @JohnLauner

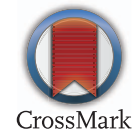

To cite Launer J. Postgrad Med J 2015;91:413-414.

Published Online First 16 June 2015 


\section{On reflection}

Postgrad Med J 2015;91:413-414

doi:10.1136/postgradmedj-2015-133574

\section{REFERENCES}

1 Moran M. The Top 10 Reasons Students Cannot cite Wikipedia. http://www.findingdulcinea.com/news/ education/2010/march/The-Top-10-Reasons-StudentsCannot-Cite-or-Rely-on-Wikipedia.html (accessed 1 Jun 2015).

2 Harvard Guide to Using Sources: What's wrong with Wikipedia? http://isites.harvard.edu/icb/icb.do? keyword=k70847\&pageid=icb.page346376 (accessed 1 Jun 2015)

3 Bould MD, Hladkowicz ES, Pigford AE, et al. References that anyone can edit: review of Wikipedia citations in peer reviewed health science literature. $B M J$ 2014;348:1585.

4 Giles J. Special Report: Internet Encyclopaedias go Head to Head. Nature 2005:438:900-901.

5 Rajagopalan MS, Khanna VK, Leiter Y, et al. Patient-Oriented Cancer Information on the Internet: A comparison of Wikipedia and a professionally maintained database. J Onc Pract 2011;7:319-23.

6 Launer J. Sex Versus Survival: The Life and Ideas of Sabina Spielrein. London and New York: Duckworth/ Overlook, 2015.

7 MIT Technology Review: The Decline of Wikipedia http://www.technologyreview.com/featuredstory/520446/ the-decline-of-wikipedia/ (accessed 1 Jun 2015).

8 Rasberry L. Citing Wikipedia. BMJ 2014;348:1819.

9 Wikipedia: Statistics https://en.wikipedia.org/wiki/ Wikipedia:Statistics (accessed 1 Jun 2015). 